\title{
Arrhythmogenic right ventricular cardiomyopathy
}

INSERM

\section{Source}

INSERM. (1999). Orphanet: an online rare disease and orphan drug data base.

Arrhythmogenic right ventricular cardiomyopathy. ORPHA:247

\begin{abstract}
A heart muscle disease that consists in progressive dystrophy of primarily the right ventricular myocardium with fibro-fatty replacement and ventricular dilation, and that is clinically characterized by ventricular arrhythmias and a risk of sudden cardiac death.
\end{abstract}

